\title{
Heat Treatment Effect on the Fatigue Characteristics of Additive Manufactured Stainless Steel 316L
}

\author{
Ashwin Polishetty and Guy Littlefair
}

\begin{abstract}
Stainless steel is an age old and popular alloy known for its high corrosion resistance. This paper is an attempt to explore ways to enhance the fatigue characteristics using heat treatment. The additive manufacturing technique used in this paper is based on Selective Laser Melting (SLM). The material used in this paper is SLM Stainless steel 316L. The specimen printed using SLM technique are subjected to low cycle fatigue tests as per the ASTM standards. Out of the twelve printed specimens, two sets for as-built and heat-treated were separated. A set of six was heat-treated at recrystallisation temperature of $700^{\circ} \mathrm{C}$ for 2 hours and air cooled. Two specimen each for the as-built and heat-treated category were reserved for tensile testing to evaluate the yield strength, ultimate tensile strength and strain. The remaining eight printed specimen of as-built and heat-treated were allotted for fatigue testing (four each of as-built and heat-treated). After tensile tests, fatigue tests were conducted on the specimens at mean stress equals to $75 \%, 70 \%, 65 \%$ and $60 \%$ of tensile strength, keeping stress ratio, $r=0.5$ and at frequency of $5 \mathrm{~Hz}$. Number of cycles to failure were obtained for each specimen for similar loading conditions to plot the $\mathrm{S}-\mathrm{N}$ curve. The paper concludes by making an analogy in the fatigue characteristic of as-built and heat-treated specimen.
\end{abstract}

Index Terms-Fatigue, stainless steel $316 \mathrm{~L}$, additive manufacturing, selective laser melting and heat treatment.

\section{INTRODUCTION}

Steel is defined as an Iron-Carbon alloy containing varying amounts of carbon from 0.008 to $2.1 \%$. The variation of carbon concentrations and addition of alloying elements varies the properties of steels drastically [1]. Steels are present in various phases depending on the eutectoid temperature. The physical properties exhibited by steels depend largely on the phases present after the phase transformation. The phases present in steels after heat treatment can be manipulated by addition of alloying elements. The alloying elements shift the phase diagram depending on their weightage. Depending on the microstructural phase, steels are classified as Austenitic Stainless Steel, Ferritic Stainless Steel, Duplex Stainless Steel and Martensitic Stainless Steel [2]. Austenitic Stainless Steel (316L) is a popular choice in design applications because of its high corrosive resistance. The potential areas of application are petroleum, chemical, biomaterial and

Manuscript received September 24, 2018; revised April 2, 2019. This work was supported in part by the Deakin University, Australia.

The authors are with Machining and Machinability research group, AUT University, Auckland 1010, New Zealand (e-mail: ashwin.polishetty@aut.ac.nz, guy.littlefair@aut.ac.nz). automobile industries. The stainless-steel parts are generally produced by conventional methods like casting, forging, or extrusion. Due to the high chromium content, machining is a drawback but new technology such as additive manufacturing has solved the issue to an extent in certain application involving complex shapes and monolithic structures. There are lot of unknowns especially on the fatigue and creep of additive manufactured components.

Though for production of complex parts, they need to be machined or welded, which may cause inter-granular corrosion affecting the mechanical properties of the part [3]. Hence, various new advanced manufacturing technologies are developed. These processes make production of complex parts easier, without affecting the mechanical properties of the material [4], [5]. Additive Manufacturing (AM) technologies can be processed using various scientific process and methods. Such as different layer-wise production processes like 3-D printing, stereo lithography, Selective Laser Sintering (SLS) or Selective Laser Melting (SLM), electron beam melting (EBM), and many more. All the technique of advanced production focus on expanding the areas of application by developing new materials and improving the quality of part by optimizing the material integrity to improve the density, surface quality and the mechanical properties respectively [6]. Some Advanced processes have already attained a maturity, where the parts manufactured are utilized directly in the end application [7].

Selective Laser Melting (SLM), is a type of AM technique, which involves layer by layer manufacturing using a micrometer sized particle powder and laser beam as source of heat to melt and bind the powder [8], [9]. The specimen manufactured is free from the fabrication of materials. A complete 3D model of the specimen is made using CAD software. The model is then divided in various layers of micrometer thickness with the help of a customized AM software [8]. In SLM, the laser performs an essential operation of scanning of the thin layer of the powder which are deposited on the base of the chamber. The process of material forming goes in the same direction of laser beam scanning. Sequentially, elongated lines of molten powder are filled in every cross-section of the part. The quality of the specimen manufactured by SLM method will depend on the layer thickness, powder size, power of the laser beam, scanning speed, hutching, the orientation and build-direction [9]. Hence, SLM manufacturing process is parameter sensitive process. SLM manufactured specimens of 316 stainless steel show high tensile, compression, hardness, and part density as compared to wrought or cast materials, this is because the parts are subjected to high cooling rates during manufacturing process which results for a short grain microstructure. 


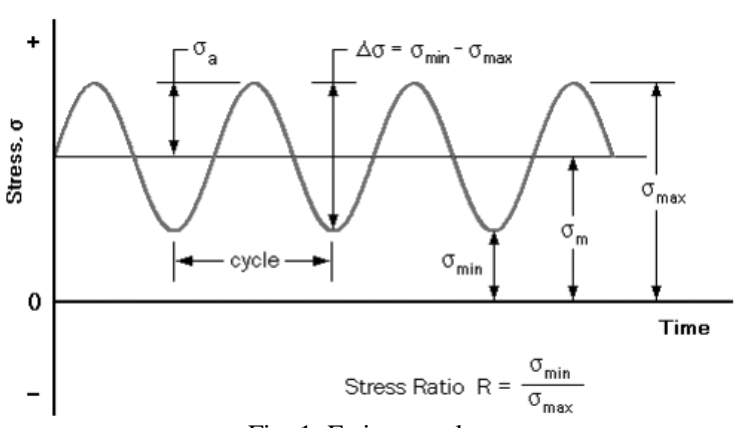

Fig. 1. Fatigue cycle.

Though, they are reported with low fatigue strengths, caused by the defects during production like porosity, inclusions and anisotropy [10]. Fatigue is a limited, dynamic and permanent deformation in a structure which occurs to the materials being subjected to fluctuating or repeated stress and strain cycles. This results in development of crack in the material after a specific number of cycles [11].

Fatigue occurs by the simultaneous actions of repeated, tensile stresses and plastic strain. If any of the above stresses and strain is absent, then initiation and propagation of fatigue crack will not occur. Fatigue crack initiates because of cyclic stress, and tensile stress results in crack propagation [11]. A typical fatigue cycle is shown in fig.1. Unlike other materials, the mechanical properties of the stainless steel can be changed by heat treatment [12]. There are many heat treatment processes like annealing, normalizing, hardening and tempering. It is a combination of simultaneously heating and then cooling the specimen to obtain better mechanical properties such as hardness, toughness, yield strength, tensile strength, etc. (most of the static and dynamic mechanical properties) and a fine grain microstructure of the specimen [13].

\section{A. Literature Review}

There are various research works carried out on the SLM process especially titanium alloys, mostly on alloy Ti-6Al-4V [14]. The results show that the SLM processed specimens of Ti-6Al-4V alloy can achieve high specific strengths, even in case of repeated loading and crack growth [15], [16]. However, for optimizing properties like ductility, hardness, etc. specific treatments were necessary after the SLM production process. This was due to the defects such as porosity caused during the production process [16]. Similarly, there are research studies conducted on aluminum alloys, steels and nickel alloys focusing on static and dynamic properties, the process of production and microstructure [17]. Even, there are various reports on the properties of alloys produced by SLM and other conventionally manufacturing process [15], [16]. However, the number of papers on processing, surface finish, and the defects occurred during production in SLM 316L stainless steel are very less.

There are results of fatigue strength of SLM 17-4PH stainless steel subjected to repeated bending by Sehrt and Witt in 2010. For better results the specimens were produced in horizontal orientation. However, tensile fatigue tests are more severe than bending fatigue tests [18]. The results of investigation on fatigue performance of SLM 316L and SLM 17-4H stainless steel was published by Spierings and Starr in 2013. The specimens were produced in vertical orientation with Checker board type laser scanning strategy. It stated that surface quality have a comparable effect in fatigue life [19]. Strain-controlled testing of notched specimens was not studied. The investigation conducted on SLM 304 stainless steel by Guan and Wang in 2013 stated that the mechanical properties increases with increasing interval of layers.

The specimens were produced in vertical orientation [20]. Riemer and Leuders (2014) in their work on SLM 316L stainless steel stated that there is no significant effect of heat treatment on monotonic properties of the specimen [21]. The specimen used were standard compact tension fatigue testing specimen. Increase in ductility were reported in both the specimens. The tests were conducted on Universal Testing Machine. However, SLM 316L stainless steel showed similar fatigue properties to conventionally manufactured material in their as-built conditions. Even, Fatigue behavior of SLM 17-4Ph and conventionally manufactured 17-4 PH were studied and compared. Rotating bending tests were performed on the specimens by Akita and Uemastu in 2016. It was noted that due to lower hardness, SLM 17-4PH exhibited lower fatigue strengths [22]. However, SLM specimens were more resistant to fatigue crack propagation than conventional manufactured sample. In 2016, Deev and Kuznetcov investigated the mechanical properties and impact strength of $316 \mathrm{~L}$ stainless steel under room temperature. The specimens were built in vertical orientation with different building directions. the research suggested that the impact strength of the specimen is dependent on the power of the laser beam[23]. Although no effects were found on the hardness values of the specimen. According to the work of Suryawanshi and Prashanth (2016), tensile and toughness property of $316 \mathrm{~L}$ stainless steel produced by SLM with both single melt and checker board type scanning strategy remain anisotropic in nature [24]. Moreover, reduction in stress intensity factor for fatigue crack initiation and propagation was also found during investigation. Furthermore, Liu and Cheng also investigated formation of microstructures during deposition process and the phase transformation under different heat conditions. The specimen used for investigation ware SLM AISI 431 stainless steel. It was reported that stainless steel had optimal mechanical properties after heat treatment at $1050^{\circ} \mathrm{C}$ [25]. From the above review, it is eminent that SLM 316L stainless steel have comparable properties to that of conventionally built materials.

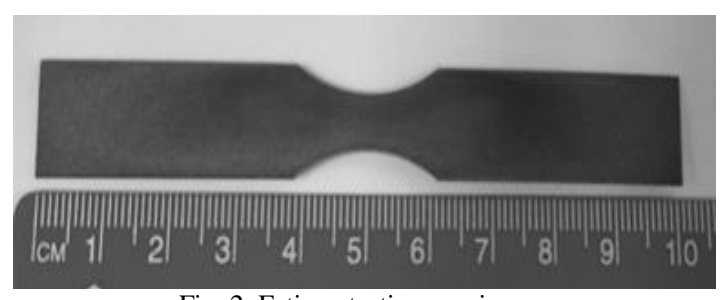

Fig. 2. Fatigue testing specimen.

TABLE I: Fatigue Testing SPecimen Dimensions

\begin{tabular}{|l|l|}
\hline Parameters & $(\mathbf{m m})$ \\
\hline Length & 110 \\
\hline Width & 14 \\
\hline Thickness & 3.5 \\
\hline Radius of Notch & 7 \\
\hline Width at notch & 7 \\
\hline
\end{tabular}


However, there is very little knowledge regarding the behavior of fatigue crack growth and initiation of $316 \mathrm{~L}$ stainless steel flat sheet specimen produced by SLM, and stress relived by heat treatment. This paper is an attempt to fill the research gap.

\section{EXPERIMENTAL DESIGN}

This paper investigates and compares the fatigue behavior of SLM 316L stainless steel, as-built and heat-treated respectively using low cycle reverse fatigue theory. The experimental design for this paper is divided in to three parts.

\section{A. Specimen Preparation}

The specimens required for fatigue testing are designed as per the ASTM standards.

TABLE II: SLM PRINT CONDITIONS

\begin{tabular}{|l|l|}
\hline Scan Speed $(\mathrm{mm} / \mathrm{s})$ & 560 \\
\hline Power output $(\mathrm{W})$ & 175 \\
\hline Offset $(\mathrm{mm})$ & 2 \\
\hline Exposure time $(\mu \mathrm{s})$ & 1 \\
\hline Layer thickness $(\mathrm{mm})$ & 0.03 \\
\hline
\end{tabular}

Fatigue Specimen with rectangular cross-section were built on SLM 125 machine in horizontal orientation as shown in Fig. 2. All dimensions are in millimeters and defined in table I. Horizontal orientation was considered while printing for optimum results. The specimens were printed in a block of size $110 \times 80 \times 14 \mathrm{~mm}$. Using a wire cut EDM machine, the specimen was sliced to the thickness of $3.5 \mathrm{~mm}$. Twelve specimens were generated after cutting process. The cut specimens were checked for porosity and defects. The defect free specimens were further polished to a micrometer finish and checked for stress concentration zones and cracks. Out of the twelve printed specimens, two sets of six each for as-built and heat-treated were separated.

\section{B. Heat treatment Process}

A set of six specimens were heat-treated at recrystallisation temperature. The selected specimen was heat-treated in a furnace supplied with argon gas to ensure vacuum environment and prevent oxidation. The defined heat treatment parameters are $700^{\circ} \mathrm{C}$ and 2 hours at the rate of $10^{\circ}$ $\mathrm{C} / \mathrm{min}$. The specimens were air cooled.

\section{Fatigue Testing}

In this stage, all the eight specimens as-built and heat-treated were subjected to low cycle fatigue testing. Two specimen each for the as-built and heat-treated category were reserved for tensile testing to evaluate the yield strength, Ultimate Tensile Strength (UTS) and strain. These properties play a significant role in deciding the parameters and loading conditions for fatigue testing. Tensile testing was done on an Instron tensile testing machine of $100 \mathrm{KN}$ capacity, as shown in Fig. 3. The fatigue testing was conducted on the a specially designed fatigue rig. Fatigue testing is a complex process requiring simultaneous monitoring of the support systems involved till the specimen fails. This may require hours to a day of monitoring time in regular intervals.

The authors have ensured the confidence in the results by early detection and avoiding pre-mature failures due to slipping and other mechanical conditions. To ensure repeatability in the outcome, each category as-built and heat-treated was tested at least twice especially on tensile testing. Considering the economics and financial viability of printing a SLM specimen. The authors have attempted to publish a quality and reliable results using the number of defect free specimens in hand. Fatigue tests were conducted on the eight specimens of as-built and heat-treated respectively. The test was stress-controlled. The mean stresses for the four specimens consisting of as-built and heat-treated category were $75 \%, 70 \%, 65 \%$ and $60 \%$ of UTS. Stress ratio, $r=0.5$ and the frequency, $f=5 \mathrm{~Hz}$ were constant for each specimen. During the fatigue testing experiment, the stress amplitude and the number of cycles to failure of each specimens were recorded. The fatigue testing process consists of applying stress of $0.1 \%$ lower of the ultimate tensile strength on the specimen till the failure, to record the number of cycles (N) before failure. Similarly, fatigue tests with $0.1 \%$ lower stress of the previous stress will be applied on remaining specimens to produce a four-point $\mathrm{S}-\mathrm{N}$ curve. The selected cycle loading parameters are shown in Table III.

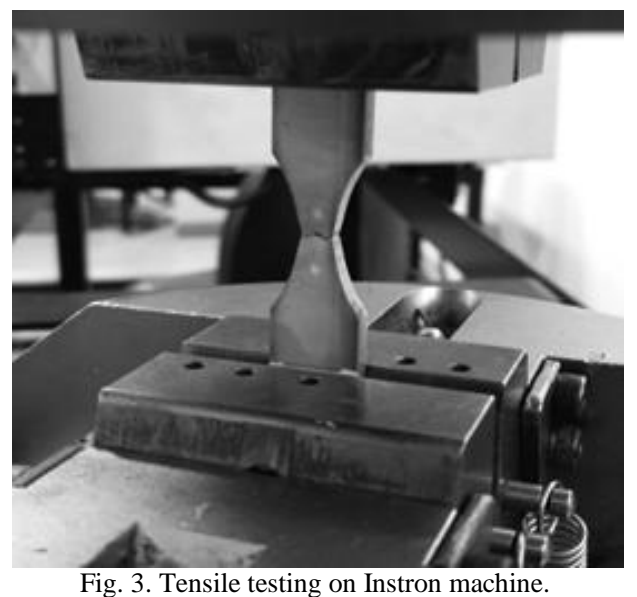

TABLE III: CYCLIC LOADING PARAMETERS

\begin{tabular}{|l|l|l|l|l|}
\hline \multicolumn{1}{|l}{ TABLE III: CYCLIC LOADING PARAMETERS } \\
\hline \multirow{4}{*}{ Specimen } & As-built & Heat-treated \\
& $\begin{array}{l}\text { Stress } \\
\text { amplitude } \\
(\mathrm{MPa})\end{array}$ & $\begin{array}{l}\text { Mean } \\
\text { stress } \\
(\mathrm{MPa})\end{array}$ & $\begin{array}{l}\text { Stress } \\
\text { amplitude } \\
(\mathrm{MPa})\end{array}$ & $\begin{array}{l}\text { Mean } \\
\text { stress } \\
(\mathrm{MPa})\end{array}$ \\
\hline 1 & 143 & 10 & 87 & 12 \\
\hline 2 & 147 & 11 & 141 & 11 \\
\hline 3 & 151 & 10 & 156 & 10 \\
\hline 4 & 182 & 12 & 163 & 10 \\
\hline
\end{tabular}

\section{RESULTS AND DISCUSSION}

The results obtained from the experiments are divided in to two parts: tensile and fatigue test results. Table IV shows the tensile test results for as-built and heat-treated specimen. From the data, we can observe that the UTS of heat-treated specimens are higher than as-built specimens. Moreover, yield stress of heat-treated specimen is lower than as-built specimens.

This means the elastic region of heat-treated specimens is lower than as-built. The plastic region is higher which indicate heat-treated specimens are more ductile than the as-built specimens. The stress-strain curve for the as-built 
and heat-treated specimen is given in Fig. 4 and Fig. 5 respectively. From the graphs, it can be observed that heat-treated specimen has higher strain values then as-built specimen. This may be attributed to the slightly elongated grain microstructure developed during heat-treatment. This results in increase in ductility and relives stresses which were induced during the manufacturing process. The UTS for the heat-treated specimens are higher than as built specimen. Moreover, yield stress of heat-treated specimen is lower which means the elastic region is lower than as-built ones and the plastic region is more, making them more ductile. A general prediction can be done based on the tensile test results with respect to the expected fatigue test results. To ensure repeatability, the average value of the tensile test results on the two specimens is taken into consideration.

\begin{tabular}{|l|l|l|}
\multicolumn{3}{|c|}{ TABLE IV: TENSILE TEST RESULTS } \\
\hline Stress (MPa) & As-built & Heat-treated \\
\hline Ultimate tensile stress & 630 & 652 \\
\hline Yield stress & 471 & 390 \\
\hline Young's Modulus & 2.4 & 2.2 \\
\hline
\end{tabular}

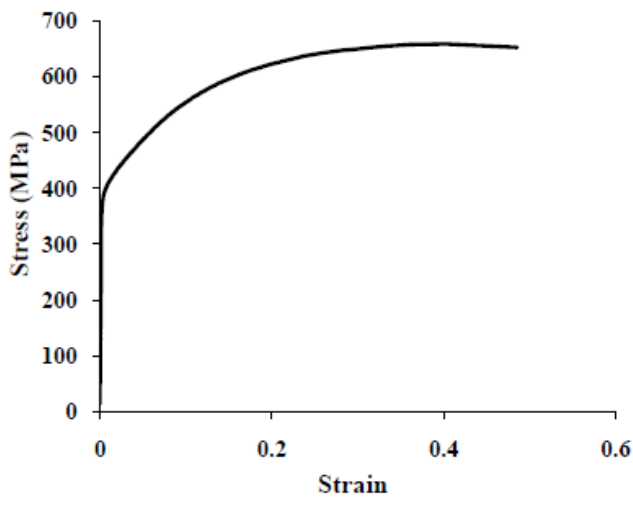

Fig. 4. Stress-Strain curve for as-built specimen.

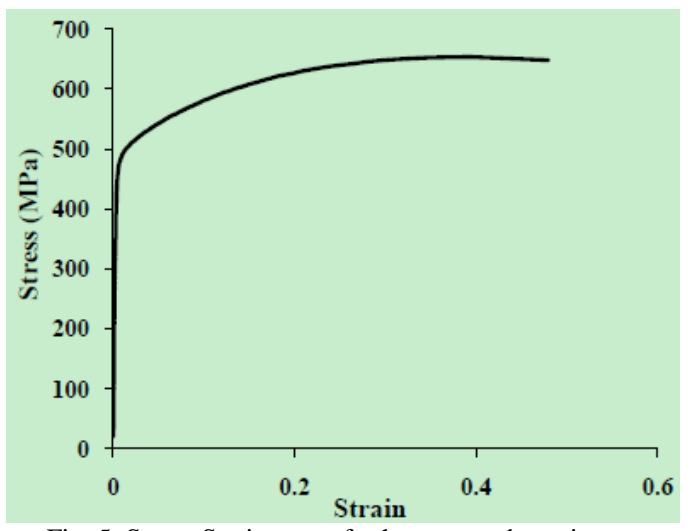

Fig. 5. Stress-Strain curve for heat-treated specimen.

The S-N curve plotted in log scale for as-built and heat-treated specimen is shown in Fig. 6 and Fig. 7 respectively. It can be observed from table $\mathrm{V}$ that on an average, the heat-treated specimens have higher number of cycles to failure than the as-built samples at same stress levels. This is because of the lower internal stress present in the heat-treated specimens. This can also be due to the refinement of microstructure leading to increase in ductility in the specimen. A few aberrations can be observed regards to the fatigue test results where there was a pre-mature failures or slippage occurring can be noticed, as in as-built, specimen 4. Overall, the authors have conveyed their observations regards to improvement in fatigue characteristics upon heat treatment. The results obtained are true to the some of the interesting observation done by previous researchers regards to microstructure grain refinement due to heat treatment and its effect on fatigue life.

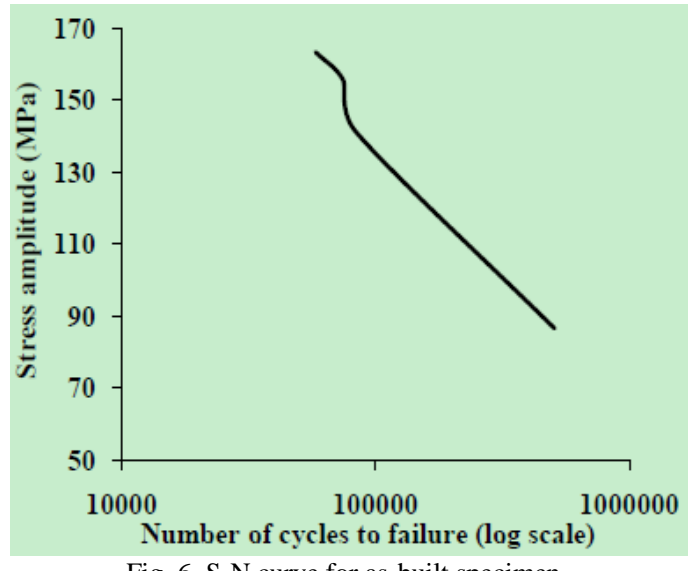

Fig. 6. S-N curve for as-built specimen.

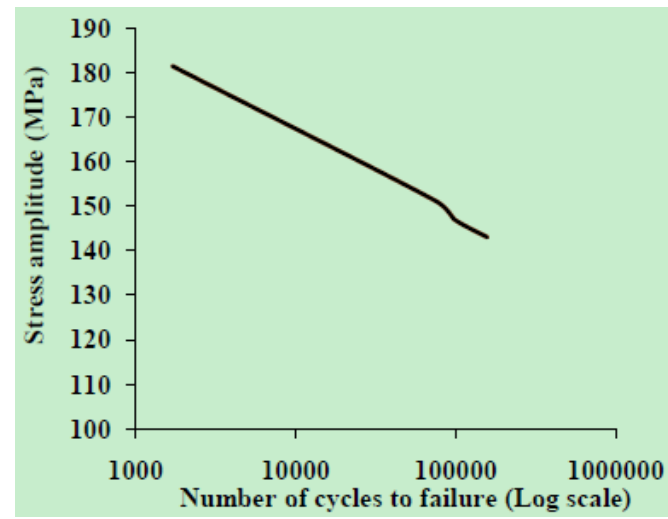

Fig. 7. S-N curve for heat treated specimen.

\begin{tabular}{|l|l|l|}
\multicolumn{2}{|c}{ TABLE V: NUMBER OF CYCLES TO FAILURE } \\
\hline & As-built & Heat-treated \\
\hline Specimens & No. of cycles to failure & No. of cycles to failure \\
\hline 1 & 15790 & 50817 \\
\hline 2 & 98450 & 83914 \\
\hline 3 & 75000 & 74800 \\
\hline 4 & 1700 & 58324 \\
\hline
\end{tabular}

\section{CONCLUSION}

The fatigue characteristics for as built and heat-treated specimen had varying characteristics. The recrystallisation of the microstructure due to heat treatment influenced fatigue characteristics. Heat-treated specimens have increased workability and ductility whereas as-built specimens are brittle.

\section{FUTURE WORK}

The tests performed in this paper were stress controlled fatigue tests. It would be advantageous in terms of fatigue life, to evaluate the fatigue characteristics using a combination strain controlled and bending moment tests. Investigation on fatigue crack propagation can also be carried out to understand the fatigue behaviour of additive manufactured materials. 


\section{ACKNOWLEDGMENT}

The authors would like to acknowledge Deakin University, Australia for the material and laboratory support to conduct the experiments.

\section{REFERENCES}

[1] A. Polishetty et al., "A preliminary study on machinability assessment of nanobainite steel," in Proc. ASME 2013 International Mechanical Engineering Congress and Exposition, 2013, American Society of Mechanical Engineers.

[2] A. Polishetty et al., "A preliminary study on machinability of super austenitic stainless steel," in Proc. ASME 2015 International Mechanical Engineering Congress and Exposition, 2015, American Society of Mechanical Engineers.

[3] C. García et al., "Pitting corrosion behaviour of PM austenitic stainless steels sintered in nitrogen-hydrogen atmosphere," Corrosion Science, vol. 49 , no. 4, pp. 1718-1736, 2007

[4] S. Kumar and J. P. Kruth, "Composites by rapid prototyping technology," Materials \& Design, vol. 31, no. 2, pp. 850-856, 2010.

[5] Q. Li, I. Kucukkoc, and D. Z. Zhang, Production Planning in Additive Manufacturing and $3 D$ Printing, Computers \& Operations Research, vol. 83, pp. 157-172, 2017.

[6] J. P. Kruth et al., "Selective laser melting of iron-based powder," Journal of Materials Processing Technology, vol. 149, no. 1, pp. 616-622, 2004.

[7] H. Lan, "Web-based rapid prototyping and manufacturing systems: A review," Computers in Industry, vol. 60, no. 9, pp. 643-656, 2009.

[8] A. Polishetty et al., "Cutting force and surface finish analysis of machining additive manufactured titanium alloy Ti-6Al-4V," Procedia Manufacturing, vol. 7, pp. 284-289, 2017.

[9] M. Shunmugavel, A. Polishetty, and G. Littlefair, "Microstructure and mechanical properties of wrought and additive manufactured Ti-6Al-4V cylindrical bars," Procedia Technology, vol. 20, pp. 231-236, 2015.

[10] N. Shamsaei et al., "An overview of Direct Laser Deposition for additive manufacturing; Part II: Mechanical behavior, process parameter optimization and control," Additive Manufacturing, 2015, vol. 8, pp. 12-35.

[11] H. E. Boyer, Atlas of Fatigue Curves, Asm International, 1985.

[12] Y. Liu et al., "Effects of heat treatment on microstructure and tensile properties of laser melting deposited AISI 431 martensitic stainless steel," Materials Science and Engineering: A, vol. 666, pp. 27-33, 2016.

[13] D. Fadare, T. Fadara, and O. Akanbi, "Effect of heat treatment on mechanical properties and microstructure of NST 37-2 steel," Journal of Minerals and Materials Characterization and Engineering, vol. 10, no. 3, p. 299, 2011.

[14] V. Seyda, N. Kaufmann, and C. Emmelmann, "Investigation of aging processes of Ti-6Al-4 V powder material in laser melting," Physics Procedia, vol. 39, pp. 425-431, 2012.

[15] B. Van Hooreweder et al., "Analysis of fracture toughness and crack propagation of Ti6A14V produced by selective laser melting," Advanced Engineering Materials, vol. 14, no. 1-2, pp. 92-97, 2012.

[16] S. Leuders et al., "On the mechanical behaviour of titanium alloy TiAl6V4 manufactured by selective laser melting: Fatigue resistance and crack growth performance," International Journal of Fatigue, 2013, vol. 48, pp. 300-307.
[17] T. Vilaro et al., "Microstructural and mechanical approaches of the selective laser melting process applied to a nickel-base superalloy," Materials Science and Engineering: A, 2012, vol. 534, pp. 446-451.

[18] J. Sehrt and G. Witt, "Dynamic strength and fracture toughness analysis of beam melted parts," in Proc. the 36th International MATADOR Conference, 2010, Springer.

[19] A. B. Spierings, T. L. Starr, and K. Wegener, "Fatigue performance of additive manufactured metallic parts," Rapid Prototyping Journal, 2013, vol. 19, no. 2, pp. 88-94.

[20] K. Guan et al., "Effects of processing parameters on tensile properties of selective laser melted 304 stainless steel," Materials \& Design, vol. 50, pp. 581-586, 2013.

[21] A. Riemer et al., "On the fatigue crack growth behavior in 316L stainless steel manufactured by selective laser melting," Engineering Fracture Mechanics, vol. 120, pp. 15-25, 2014.

[22] M. Akita et al., "Defect-dominated fatigue behavior in type 630 stainless steel fabricated by selective laser melting," Materials Science and Engineering: A, vol. 666, pp. 19-26, 2016.

[23] A. A. Deev, P. A. Kuznetcov, and S. N. Petrov, "Anisotropy of Mechanical Properties and its Correlation with the Structure of the Stainless Steel 316L Produced by the SLM Method," Physics Procedia, vol. 83, pp. 789-796, 2016

[24] J. Suryawanshi, K. Prashanth, and U. Ramamurty, "Mechanical behavior of selective laser melted 316L stainless steel," Materials Science and Engineering: A, 2017.

[25] Y. Liu et al., "Effects of heat treatment on microstructure and tensile properties of laser melting deposited AISI 431 martensitic stainless steel," Materials Science and Engineering: A, vol. 666, pp. 27-33, 2016.

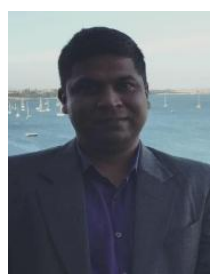

Ashwin Polishetty currently is a senior research fellow at the Faculty of Creative Technologies, AUT University. He has been actively involved in research on machinability of newly emerging, design centric materials for aerospace, bio-medical and automotive industry. He is a lead researcher of the machining and machinability group, advance manufacturing and related high-end technologies group. His research on additive manufacturing for aerospace and bio-medical industry has been a primary point of focus. He is also a reviewer for reputed journals; keynote speaker, technical and organizing committee member, session chair and article reviewer for some international conferences.

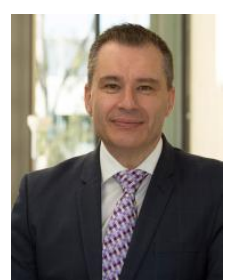

Guy Littlefair is a professor and the pro vice chancellor and dean of the Faculty of Design and Creative Technologies at Auckland University of Technology. Prior to his return to AUT in 2017, Professor Littlefair was the pro vice-chancellor for Industry and Strategic Partnerships and earlier, the dean of engineering in the Faculty of Science, Engineering and the Built Environment at Deakin University in Australia. Combined with an academic career spanning 25 years, Professor Littlefair has also had the opportunity to spend time in industry. He has been a reviewer for reputed journals; keynote speaker, technical and organizing committee member, session chair and article reviewer for some international conferences. 